\title{
Characterizing the COVID-19 Illness Experience to Inform the Study of Post-acute Sequelae and Recovery
}

\author{
Edda I. Santiago-Rodriguez ${ }^{1}$ Andres Maiorana ${ }^{1} \cdot$ Michael J. Peluso $^{2} \cdot$ Rebecca Hoh $^{2} \cdot$ Viva Tai $^{2}$ - Emily A. Fehrman ${ }^{2}$. \\ Yanel Hernandez ${ }^{2} \cdot$ Leonel Torres $^{2} \cdot$ Matthew A. Spinelli $^{2} \cdot$ Monica Gandhi $^{2} \cdot$ J. Daniel Kelly ${ }^{2} \cdot$ Jeffrey N. Martin $^{3}$. \\ Timothy J. Henrich ${ }^{4} \cdot$ Steven G. Deeks ${ }^{2}$. John A. Sauceda ${ }^{1}$
}

Accepted: 24 November 2021 / Published online: 16 December 2021

(c) International Society of Behavioral Medicine 2021

\begin{abstract}
Background There is an urgent need to fully understand the impact of variable COVID-19 experiences and the optimal management of post-acute sequelae of SARS-CoV-2 infection. We characterized the variability in the acute illness experience and ongoing recovery process from participants in a COVID-19 recovery cohort study in Northern California in 2020. Method We completed 24 semi-structured in-depth interviews with adults with confirmed positive SARV-CoV-2 nucleic acid amplification test result, had recovered or were recovering from acute infection, and underwent serial evaluations. We purposefully sampled English- and Spanish-speaking adults with asymptomatic, mild, and severe symptomatic infection, including those who were hospitalized and those with HIV co-infection. We used a thematic analysis to analyze interviews and identify salient themes.

Results After integrating the thematic analysis with clinical data, we identified key themes: (1) across symptom profiles and severity, experiencing COVID-19 was associated with psychological distress; (2) symptomatic infection carried uncertainty in symptom presentation and ongoing recovery (e.g., long COVID); and (3) health information-seeking behavior was facilitated by access to medical care and uncertainty with the recovery process.

Conclusion Our data informs the emerging field of "long COVID" research and shows a need to provide information and continuous support to persons with post-acute sequelae to ensure they feel secure along the path to recovery.
\end{abstract}

Keywords SARS-Cov-2 $\cdot$ Coronavirus $\cdot$ COVID-19 $\cdot$ Mental health $\cdot$ Recovering from COVID-19 $\cdot$ Post-acute sequelae of SARS-CoV-2 (PASC) $\cdot$ Long COVID

\section{Introduction}

There is an urgent need to fully understand the impact of variable COVID-19 experiences and the optimal management of post-acute sequelae of SARS-CoV-2 infection

John A. Sauceda

john.sauceda@ucsf.edu

1 Center for AIDS Prevention Studies, University of California, San Francisco, 550 16th Street, 3rd Floor, San Francisco, CA 94158, USA

2 Division of HIV, ID and Global Medicine, University of California, San Francisco, San Francisco, CA, USA

3 Department of Epidemiology and Biostatistics, University of California, San Francisco, San Francisco, CA, USA

4 Division of Experimental Medicine, University of California, San Francisco, San Francisco, CA, USA
(PASC) [1]. Our early understanding of the lived experiences and challenges with recovery from COVID-19 was mainly from reports in media outlets and editorials, letters, and case reports in scientific journals [2-7]. While these reports and editorials highlight unique areas to prioritize for future research, they do not leverage data from personal experiences with COVID-19 through formal qualitative research. Qualitative research methods can characterize the variability in how people define and experience their disease and recovery [8] and offer data to support development of strategies to manage persistent symptoms attributed to COVID-19.

COVID-19 has produced wide-ranging physical, neurological, and mental health effects, many of which can persist and are yet to be fully understood, leaving many individuals in a state of disease uncertainty $[9,10]$. However, lessons can be drawn from research on chronic disease management where prognoses are uncertain, such as the potential benefits 
of information-seeking behavior and leveraging a person's healthcare empowerment $[11,12]$, both of which describe how individuals process, understand, seek, and act on disease information, especially for coping with uncertainty and chronic disease [13, 14]. Qualitative research can illustrate the illness experiences and recovery trajectories in persons with a history of COVID-19 to inform the emerging field of post-acute sequelae management given the uncertainties that remain regarding its pathogenesis, treatment options, and emerging evidence that not all individuals experience a rapid or complete recovery [15].

\section{Objective}

We conducted in-depth interviews with people with previously documented SARS-CoV-2 infection who had entered the "recovery phase" from COVID-19 and were able to attend at least one in-person visit at our study center. The sample experienced a spectrum of severity of the acute SARS-CoV-2 illness, from asymptomatic infection to requiring hospitalization. We included people living with HIV (PLWH) to also understand the convergence of the two pandemics [16]. Participants were first enrolled in a parent observational cohort study, the Long-term Immunological Impact of Novel Coronavirus (LIINC) COVID-19 recovery cohort study (NCT04362150) (www.liincstudy.org) [17]. LIINC explores immunologic responses at different stages of convalescence to understand the effects of SARS-CoV-2 over time and is based within an academic care and research center. The clinical course for each participant is also provided to contextualize the interview data.

\section{Methods}

\section{Ethics Approval}

The study was approved by the University's Committee on Human Research. Participants provided written consent for the parent study and sharing of clinical data and verbal consent for the interview.

\section{Eligibility Criteria}

The LIINC study is based within an academic care and research center in Northern California. In April 2020, participants with documented SARS-CoV-2 infection confirmed on nucleic acid amplification testing were eligible to enroll during the early recovery phase from COVID-19 (defined as 3-10 weeks following illness onset). Any adult with confirmed infection was eligible; eligibility was not contingent on any particular clinical characteristics of acute infection or recovery. Participants were recruited through clinician and participant self-referral, an online web portal (www.liincstudy.org), clinicaltrials.gov (NCT04362150), local media advertisements, and via our electronic medical record system. Following enrollment, participants were monitored monthly for up to 4 months and quarterly thereafter. Detailed clinical questionnaires were administered by a research coordinator supervised by a study physician (including demographic information, characterization of the acute illness, circumstances of diagnosis and treatment, identification of any symptoms during the acute and recovery phases, comorbid medical conditions, and concomitant medications), and biospecimen collection (including blood, whole unstimulated saliva, and gingival crevice fluid collection). Participants from the LIINC study were then enrolled in this separate qualitative study if interested.

\section{Procedures}

Clinical staff introduced the qualitative study to LIINC participants; willing participants were then referred to the social science research team who conducted this study. A total of 42 participants were referred by the LIINC staff. The social science research team contacted potential participants through email, phone call, or text message based upon their preferences. Participants who were reached and available to participate were scheduled for a semi-structured in-depth interview through privacy-compliant video conference software or telephone. We used a purposeful sampling method by having weekly discussions with the LIINC team during active enrollment about the demographic characteristics of their referrals based on ethnicity/race, HIV status, language, and occupation. The purpose of this sampling strategy was to ensure diversity.

Interviews were conducted between June and October 2020, were of 30 to $90 \mathrm{~min}$ in duration, and were conducted in English or Spanish by one of two fully bilingual qualitative researchers. The semi-structured interview guide was designed to explore areas related to COVID-19 such as knowledge, prevention methods, symptoms, testing, different recovery experiences, access to resources, housing stability, food insecurity, and economic stability. Interviews were audio-recorded and transcribed ad verbatim. After the interview, each participant received a $\$ 50$ gift card. We interviewed until saturation (i.e., redundancy in narratives, no new insights), which occurred after 24 interviews.

\section{Analysis Plan}

Data analysis was iterative with weekly sessions occurring over a 2-month period. The authorship team included experts in psychology, infectious disease medicine, anthropology, and public health and expertise in qualitative research with people living with HIV in Spanish and English. We used 
thematic analysis to systematically identify and organize patterns (i.e., themes) throughout a set of transcript data [18]. A thematic analysis is a flexible method for explorative studies using both inductive and deductive reasoning to identify patterns in the data [19]. We examined the perspectives of different research participants, highlighting similarities and differences while also generating unanticipated insights [20, 21].

All interview transcripts were uploaded onto Dedoose [22], a web-based program to organize and manage qualitative data. Two authors (EIS and AM), who were also the interviewers, then reviewed a subset of two transcripts to identify initial impressions and develop an initial codebook. The codebook was developed using deductive and inductive codes based on the interview questions and themes emerging from the interviews. Using the initial coding as a guide, these two authors developed and refined a final codebook that they applied to the remaining interviews. Following standard practice in qualitative research, two independent analysts coded the transcripts, and each transcript was coded by a bilingual primary coder (social-community psychologist and public health practitioner) and reviewed by a bilingual secondary coder (medical anthropologist). For this analysis, we reviewed the coded texts in their original language related to symptoms, treatment, and recovery experiences among participants. English translation of Spanish quotes is provided for original meaning. The team then had sessions approximately every other week for 2 months to discuss and summarize the texts. Emerging results and disagreements regarding coding were discussed with the senior author (health psychologist) and a co-principal investigator (infectious disease physician and researcher). Additionally, we presented preliminary findings to the clinical cohort staff to incorporate feedback and confirm findings based on their clinical evaluations with these participants who were referred to our study. Similarly, our infectious disease physician-scientist co-authors were critical in helping verify our themes based on their own clinical care and research experiences with the study population.

We also summarized anonymized clinical evaluation data from participants' initial LIINC visit. These data are presented for each participant's first quote to help contextualize their narratives. We present self-reported demographic information, exposures, symptoms, symptom onset and severity, presence of persistent symptoms, and treatments administered for COVID-19 and mental health during their illness course. For asymptomatic infections, we report the date of the positive SARS-CoV-2 test result, whereas for symptomatic infection, we report date of symptom onset. Participants with symptomatic infection were asked to rate how good or bad their health was during the worst point of illness with COVID-19, from 0 (worst) to 100 (best). This is labeled a health score. For participants with asymptomatic infection, the health score represented how good or bad their self-perceived health was immediately before their positive test result. Missing data or non-response to clinical data questionnaires was denoted by the phrase "none reported."

\section{Results}

\section{Demographics}

The median age of 24 participants was 49 , and most were men $(62.5 \%)$ and white $(66.7 \%)$. Half of our sample $(50.0 \%)$ was Latinx/Hispanic. Nine participants reported prior hospitalization due to COVID-19, six of whom required oxygen support. Out of the nine, three received care in an intensive care unit, and two required mechanical ventilation. Eight participants were living with HIV. Six participants completed the interview in Spanish.

We started all interviews by asking about how participants learned about COVID-19 at the start of the pandemic and where they sourced their information. We then transitioned to discussing participants' experiences with COVID19, the emotional impact of having a confirmed COVID-19 diagnosis, and the factors influencing the recovery process. We report participants by identification numbers and general descriptors to maximize confidentiality.

\section{Asymptomatic Infection}

Although some participants were categorized as having asymptomatic infection, they described deep concern over their diagnosis and highlighted the benefits of having support and access to medical care. Participant \#8, whose health score was $65 / 100$ before diagnosis, stated that his experience with COVID-19 was informed by living with HIV and other comorbidities. His access to HIV care provided a source of information and support since he expected to be at high risk for COVID-19 disease based on his medical history.

"I felt highly at risk because I've had pneumonia about five times, and I've had multidrug-resistant tuberculosis, and I'm HIV positive....and a lot of scar tissue in my lungs...made me afraid that I would get it."

Participant \#8: Older White gay male. Exposure: Travel within U.S. Date of diagnosis: Spring 2020. Symptoms: Asymptomatic. Persistent symptoms: None reported. Health score: 65 out of 100. Mental health: Reported moderately depressed or anxious during diagnosis. Treatment: None reported.

Another factor in their recovery was how participants could actively benefit from their health information-seeking behavior by having access to medical care and providers. 
“...My doctor is an infectious disease specialist, and I asked her about it....I asked my nurse about it, who is in the same clinic as my doctor. And also news and media outlets. I just tried my best to look for the facts."

Similarly, participant \#24, a Spanish-speaking woman and caregiver to her two children with serious medical conditions, and whose health score was 70/100 before her diagnosis, described the support she had by having access to a medical team after testing positive for SARS-CoV-2 prior to scheduled surgical procedure. The following quote also highlights how she actively sought COVID-related health information.

"My medical team at [hospital]. Very good, also the doctor who was going to operate on me, who is not my primary doctor, the orthopedist, called me and was super, very kind, and with lots of empathy. All of them with empathy."

"I looked into a study at Harvard. Because I was interested in knowing about the symptoms, about the recovery process, about how many people had recovered. That Harvard study was like a map to follow. That is what I followed to monitor myself to see if I got any of the symptoms mentioned there that one may feel." "Mi equipo médico de la [hospital]. Muy bueno, inclusive el doctor que me iba a hacer la operación, que no es mi doctor primario, es el ortopedista, me llamó y fue super, muy amable, y tuvo mucha empatía. Todos con empatía,"

"Busqué en un estudio de Harvard. Porque me interesaba saber que lo síntomas, que la forma de recuperación, que cuántas personas se habían recuperado. Era como un mapa a seguir ese estudio de Harvard. Eso fue lo que yo seguí como para monitorearme si me daban cualquier síntoma de los que dice ahí que uno pudiera sentir."

Participant \#24: Older adult, Latinx heterosexual female. Exposure: Community spread. Date of diagnosis: Summer 2020. Symptoms: Asymptomatic. Health score: 70 out of 100. Mental health: Severe depression or anxiety during diagnosis, prior diagnosis of mood disorder. Treatment: Reported use of antibiotic.

After receiving her diagnosis, participant \#24 explained that her primary care provider also offered her support as she anticipated the onset of illness symptoms.

"I stayed in touch with my primary doctor, he was a great support. He told me that if I had trouble breathing or if I had a high fever. But no, I monitored myself and, thank God, I didn't have any symptoms. If truth be told it was only boredom."'Mantuve la comunicación con mi doctor primario, él sí fue de mucho apoyo. Me estuvo diciendo que si yo sentía problemas de respiración o que si yo sentía fiebres muy altas. Pero no, yo me estuve monitoreando y, gracias a Dios, no tuve ningún síntoma, la verdad, más que de aburrimiento."

Health information-seeking is maximally effective when there is a noted change in outcomes, such as new knowledge gained or receipt of support, both of which were present in the narratives of participants \#8 and \#24. For example, when participant \#8 stated he sent multiple emails to his HIV medical provider to follow up on his original inquiry, he was able to receive moral support. His information seeking also led to his awareness of ongoing discussions of whether antiretroviral therapy was offering protection to people living with HIV.

"She [HIV provider] didn't respond because when I did finally catch up to her, I realized how busy she was, because that's what she does for a living. She's an infectious disease doctor...I think the only support I needed from her was just moral support...And the nurse that I have...she's really good, and she reached out to me...they called about five or six times after that to ask if I needed anything, if I needed food, if I needed this, that, the other thing."

"I heard people saying people who are on lots of antivirals, like myself, weren't getting it as readily, but I don't know the facts behind that..."

Despite the reassurances that participant \#8 received about his risk for severe COVID-19 symptoms because he was living with HIV, he was also aware of his risk for severe COVID-19 due to his diabetes.

"Well, just the fear...my immune system has been intact, so I assumed that I would be okay. But I believe I was actually more concerned with diabetes, although I wasn't informed about how COVID affects diabetes. And I still don't know to this day. And I was just more worried about that than I was about my HIV."

In documenting the "recovery" process from asymptomatic infection, the importance of social support was also evident throughout the participants' experiences. As participant \#8 stated:

“...I actually didn't have time to worry because they called me the next day. I had heard that the test results come back in like three to five days, and when they called me the very next day, I was kind of really shocked. I was like, 'What do I do now? I didn't know what to do. Then I called my partner immediately, and I said, 'I got a positive result.' And he said, 'Well we're going to quarantine then, for two weeks,' which we did. Nobody came and nobody left."

Participant \#24 had a partner whose occupation involved cleaning, and thus, he cared for her and the 
household during her isolation period while recovering from COVID-19. She thought that the cleanliness may have helped in her process of recovery.

"He always came, he cleaned me, bathed me. He disinfected everything. When we had COVID, I don't know if that may have been our success, maybe it is just my theory, because just by chance my husband works in the cleaning business." "Siempre venía, me limpiaba, me bañaba. Todo lo desinfectaba. Cuando estuvimos con el COVID, no sé si eso habrá sido el éxito de nosotros, pudiera ser como una teoría mía, porque da la casualidad que mi esposo se dedica a la industria de la limpieza"

Most importantly, there was an acute experience of psychological distress during their diagnoses. Participant \#24 stated that while she had no physical symptoms from COVID-19, she was affected emotionally.

"I didn't have any symptoms, but it affected me psychologically, because knowing that you have coronavirus impacts you emotionally and one lives with the uncertainty of not knowing what is going to happen. You ask yourself: How is it going to hit me? And if I die? And if I stop breathing? I am a very sociable person. And isolating yourself, even if you know it is for a good cause, makes you depressed. I even got to cry and that 'Ok. If I have to die, I have to die." "Como que no tenía síntomas, pero psicológicamente estaba afectada, porque saber que tienes coronavirus te impacta emocionalmente y uno vive una incertidumbre que uno sabe qué va a pasar. Te preguntas: ‘¿Cómo me irá a dar? ¿Y si me muero? ¿Y si dejo de respirar? Yo soy una persona bien sociable. Y aislarte, aunque sepas que es por una buena causa, eso te deprime. Incluso llegué a llorar y a como que «Okay. Si me tengo que morir, me tengo que morir"”

Participant \#8 expressed concern about his asymptomatic infection considering other serious medical conditions he had experienced before.

"I'm not a fearful person. I've almost died a couple of times, so nothing really bothers me or frightens me. But this is a little scary...I was afraid. I was concerned with getting it because I've had all those infections."

Overall, these two cases highlight the disease uncertainty around COVID-19, even with asymptomatic infection, and associated psychological distress. Their access to medical care providers provided support and helped facilitate information-seeking behavior.

\section{Symptomatic Infections}

Participants' symptomatic experiences with COVID-19 varied by clinical features, ranging from mild symptoms to symptoms of acute respiratory distress syndrome. Many reported persistent symptoms at the time of study enrollment. Several believed their initial COVID-19 symptom onset could be explained by another cause. For instance, participant \#15 originally confused her symptoms with allergies. She shared:

"I've had seasonal allergies in the past. So, I thought, 'Oh, maybe it's just seasonal allergies.' I had the stomach cramps and seasonal allergies. Then, a couple days later, I woke up with a bad headache, like a bad sinus headache. That's also the day my husband woke up with a fever. The combination of those things is why we both decided to get tested. I had other symptoms as well. I lost my sense of taste."

Participant \#15: Middle-aged adult, White heterosexual female. Exposure: Community spread. Symptom onset: Spring 2020. Symptoms: Fatigue, cough, shortness of breath, lost sense of smell, diarrhea and difficulty concentrating. Persistent symptoms: Difficulty concentrating and diarrhea. Health score: 60 out of 100. Mental health: Moderately depressed or anxious during illness, prior diagnosis of mood disorder. Treatment: None reported

Both participants \#17 and \#21, two middle-aged White heterosexual females, took their initial symptoms for something else: menopause and a common cold. Although they reported similar symptoms, their characterization of these symptoms was different.

"My symptoms started in a cough, and I have had this stupid cough from [month before]. At the end of [month], it was kind of confusing to me because I'm going through the change [menopause], and they say if you are going through the change, you can get a fever around the time that you menstruate. I had a 102 temperature, and I started getting a really deep cough. It was weird, because I didn't have any mucus coming up or anything. I had that stupid cough, not the fever, but the cough, up until I was diagnosed. That's what started just was the cough and body aches and the fever that I got when I first got it."

Participant \#17: Middle-aged adult, Latinx female. Exposure: Contact with known + COVID-19 case not in healthcare setting. Symptom onset: Spring 2020. Symptoms: Fever, chills, fatigue, cough, shortness of breath, sore throat, muscle aches, nausea, vomiting, loss sense of smell, trouble concentrating. Persistent symptoms: Fatigue, muscle aches, nausea and loss of smell. Health 
score: Not reported. Mental health: Not reported. Treatment: Hospitalized and required oxygen.

"I started feeling very sore, like something ran me over, all my muscles. And then, my cough started getting a little worse. And my energy started depleting. I was like, 'Oh, man, I feel like this is a really bad cold coming on.' I still thought it was allergies... when I started getting a fever... I was so tired. I could not get out of bed. I tried getting out of bed and giving my kids food and stuff. I just couldn't...I could only take a few steps."

Participant \#21: Middle-aged adult, White heterosexual female. Exposure: Community spread. Symptom onset: Spring 2020. Symptoms: Fatigue, cough, shortness of breath, lost sense of smell, diarrhea and difficulty concentrating: Persistent symptoms: Difficulty concentrating and diarrhea. Health score: 60 out of 100. Mental Health: Moderately depressed or anxious during illness, prior diagnosis of mood disorder. Treatment: None reported.

Two additional participants, \#6 and \#7, reported similar symptoms to those mentioned directly above, as well as shortness of breath, loss of taste and smell, and extreme exhaustion. Participants \#6 and \#7 provide insights into the rapid onset of severe illness and a feeling of getting "hit like a train" all at once unexpectedly.

"I flew down...to visit my friend... and I was completely fine. There were no preceding symptoms. And then I woke up the next day and I felt like various symptoms like I had a fever, I couldn't walk properly, I couldn't taste or smell anything. It all just kind of came at once. There was no, like, leading up to. You know, feeling symptoms of cold, you kind of feel that something is coming on, but this, it just hit me like a train; all at once. All these symptoms came up all at once and they were very severe - shortness of breath, everything."

Participant \#6: Middle-aged adult, Asian male. Exposure: Healthcare setting. Symptom onset: Spring 2020. Symptoms: Fever, chills, cough, fatigue, shortness of breath, muscle aches, loss sense of smell. Persistent symptoms: None. Health score: Not reported. Mental Health: None. Treatment: Hospitalized and required oxygen. Reported use of hydroxychloroquine and antibiotics.

"That night, I was not feeling too good, I went to bed, I couldn't get up no more. I thought it was just like a little virus or something, I just couldn't get up, do nothing...I tried to go to the bathroom, I lost breath. I started saying I must have the flu. I took NyQuil, I took some Theraflu and I was just taking everything I could, I tried to eat the soup, but I couldn't because it didn't have no taste to it. I felt like, 'Oh, God. What's going on?' That lasted about eight days...people was calling me seeing if I was all right or whatever, I just didn't want to be bothered by nobody."

Participant \#7: Older adult, Latinx male. Exposure: Contact with known COVID-19 case not in healthcare setting. Symptom onset: Spring 2020. Symptoms: Fever, chills, fatigue, cough, shortness of breath, runny nose, muscle aches, nausea, loss sense of smell, headache. Persistent symptoms: None reported. Health score: Not reported. Mental Health: Not reported Treatment: Hospitalized in intensive care unit and required oxygen.

The five participant narratives above (\#15, \#17, \#21, \#6, and \#7) showed that while similar symptoms were reported, their experiences with COVID-19 were heterogeneous. Some participants' symptoms persisted longer than expected. Participant \#4 shared that after 14 days with a fever, his symptoms intensified. He also emphasized deficits in memories and awareness of the severity of his symptoms and the importance of the support he received from friends.

"I was actively sick for a month. That was when I started getting concerned when everything I was hearing, and reading about in the media and that the course of this was 13 to 19 days, and then you'd start feeling better. Well, I didn't... about two weeks into it, everything else kind of intensified. I had no energy, no appetite. I stayed in bed. I was sleeping 16 hours a day. There was probably seven to 10 days quarantined in my house and in my bedroom that I don't even really remember. I was getting up and going to the bathroom. And somewhere in my mind, I was conscious to the fact that I needed to make sure that even if I wasn't eating, I had to make sure that I was getting enough fluids. So I drank a lot of carbonated seltzer water. When I began to realize what was going on around me...because there were cans of seltzer water all over my bedroom, I knew that I'd been drinking. But there was seven to ten days that I really don't remember much of anything. Now, friends said that although I sounded really sick, when they would check on me every day and talk to me or Facetime with me, I must have been able to convince people that I was still okay because not everybody was alarmed... apparently, I convinced people that I was okay when, in actuality, I wasn't."

Participant \#4: Older adult, White male. Exposure: Healthcare setting. Symptom onset: Spring 2020. Symptoms: Fever, chills, fatigue, cough, shortness of breath, runny nose, muscle aches, nausea, diarrhea, trouble concentrating, headaches. Persistent symptoms: Fatigue, 
cough, shortness of breath, runny nose, nausea and trouble concentrating. Health score: Not reported. Mental Health: Not reported. Treatment: None.

Similarly, participant \#14 shared that her symptoms were worse later in the disease course. Her symptoms worsened on day 19, and she was not fully aware of what was happening.

"The initial wave was like I was dizzy for a couple weeks and I was kind of body aches. It wasn't that bad but I lost all my taste and smell and I was really out of it, just in the head. Then around day 19 it got way worse. I thought it was just going to suck for a while. I knew I was having these headaches and couldn't think but then it got like my nerves were freaking out. I got really bad ulnar nerve pain and my muscles started twitching and these fingers went numb. Then I started to get a fever around day 20. That lasted for a week but it wasn't super high grade. It was like 100.2 or something."

Participant \#14: Middle-aged adult, Latinx female. Exposure: Contact with known COVID-19 case not in healthcare setting. Symptom onset: Spring 2020. Symptoms: Fatigue, cough, sore throat, muscle aches, diarrhea, loss sense of smell, trouble concentrating, headaches. Persistent symptoms: Trouble concentrating, headaches, loss sense of smell. Health score: Not reported. Mental Health: Not. Treatment: Reported use of steroids.

The experiences of participants \#4 and \#14 highlight the severity and burden of managing persistent COVID-19 symptoms. While the clinical evaluation data show overlapping symptoms across all the participants quoted above, their experiences were variable and intense. One common thread was confusion and uncertainty-either from processing rapid symptom onset or concerns regarding cognitive impairment following recovery from the acute phase.

\section{Experiences with Hospitalizations and Advanced Medical Attention}

Nine of the participants we interviewed accessed emergency room services and had prolonged hospitalizations or, even, intubation. A participant who was hospitalized for a month shared that he was unconscious for over a week and had no recollection of that period of time.

"I was [at the hospital] - I believe I was from March 27 or 28 to April 30. One month. When I woke up [after being unconscious], I was in intensive care. I was wearing a respirator in my mouth and I was on tubes - no, I no longer had tubes in my mouth. I had like a respirator in my nose that helped me with oxygen. I didn't know what had happened to me. And a nurse told me, 'you tested positive for Covid' - I was already a week and a half with the tubes." "Estuve [en el hospital] - yo creo que estuve del 27 o 28 marzo hasta el 30 de abril. Un mes. Cuando yo volví en si a despertar [después de estar inconsciente], yo estaba en cuidados intensivos. Estaba con un respirador en mi boca y tubos - no, ya no tenía tubos en la boca. Tenía como un respirador en la nariz que me ayudaba con oxígeno. No sabía que me había pasado. Y una enfermera me dijo, "tú saliste positivo con el Covid" - ya estaba una semana y media con los tubos."

Participant \#22: Older adult, Latinx male. Exposure: Unknown. Symptom onset: Spring 2020. Symptoms: Fever, fatigue, cough, shortness of breath, loss sense of smell, trouble concentrating. Persistent symptoms: Loss sense of smell. Health score: Not reported. Mental Health: Not reported. Treatment: Hospitalized in the intensive care unit, required oxygen and intubation.

Another participant spent 35 days at the hospital, 20 of which were in the intensive care unit. He required intubation and recalled hallucinatory-like experiences during that time. $\mathrm{He}$ also shared not being able to communicate by writing.

"There were different phases. Initially in the ER, but later that night I don't even think I remember having a choice about intubation. I was really anxious and nervous about getting intubated. All of a sudden, they came in, I'm getting intubated. I don't remember even saying, no, I don't want to do that; right? I just kind of accepted it without fighting it or questioning it. Initially, there were periods when I was intubated and the medicine would wear off, but I was semi-conscious and I remember having these hallucinations. They were really funky dreams. And it was really hard to understand everything. I was trying - at one point I was still intubated, I wanted to try to get them to call [partner's name] and I couldn't write across. I kept writing the letters over each other so they couldn't understand what the hell I was talking about."

Participant \#1: Older adult, White male. Exposure: Travel outside of the U.S. Symptom onset: Spring 2020. Symptoms: Fever, chills, fatigue, cough, shortness of breath, sore throat, muscle aches, diarrhea, loss sense of smell, trouble concentrating, headaches. Persistent symptoms: Fatigue, cough, shortness of breath, headaches. Health score: None reported. Mental Health: Not reported. Treatment: Reported use of azithromycin, albuterol. Hospitalized in the intensive care unit and required oxygen and was intubated.

Participant \#21 (described further above) was also hospitalized and suffered memory loss. In her case, she was taken to the hospital after losing consciousness during her COVID-19 illness, suffering a broken nose and head injury. 
"I decided to work a little bit because I felt like, oh, I have a great energy today. That's how it happened in the mornings. I had amazing energy. But then, an hour into it, or maybe two hours, I was completely done. And I was feeling miserable. So, that day, I tried to work from home. And after an hour, I said, 'No. I am feeling miserable. I' $m$ going to go lay down and sleep.' But I woke up... I was drenched in sweat, and my stomach was very upset. And I need to go to the bathroom, and I need to throw up. And I came back to turn on the fan. And I don't remember seeing anything after that. I might have run back to the bathroom. And then, I remember someone screaming to see if I was okay. So, I ended up fainting because I was very diaphoretic and pale. And my blood pressure apparently tanked. So, I broke my nose and split my head open. And I had to be taken to the hospital."

Common experiences among participants hospitalized were clear gaps in memory, confusion, and other neurological features, including persistent symptoms of trouble concentrating, headaches, and loss of sense of smell.

\section{COVID-19 Anxiety, Frustration, and Stress}

COVID-19 was associated with psychological distress for all participants, including participants with asymptomatic infection. This was attributed to either the uncertainty behind a diagnosis, symptom course, the initial severity of symptoms, the fear of dying, and/or concern for the health of family and friends. In some instances, predisposition to experience psychological distress was catalyzed by COVID-19. During the interviews, we asked participants what went through their mind while awaiting test results. Participant \#24 (asymptomatic case described above) shared her feelings of shock:

"I didn't have any symptoms but it affected me psychologically, because knowing that you have coronavirus impacts you emotionally and one lives with the uncertainty of not knowing what is going to happen. You ask yourself: How is it going to hit me? And if I die? And if I stop breathing?...And isolating yourself, even if you know it is for a good cause, makes you depressed. I even got to cry and that 'Ok. If I have to die, I have to die.'”“'Como que no tenía síntomas, pero psicológicamente estaba afectada, porque saber que tienes coronavirus te impacta emocionalmente y uno vive una incertidumbre que uno sabe qué va a pasar. Te preguntas: ‘¿Cómo me irá a dar? ¿Y si me muero? ¿Y si dejo de respirar?...Y aislarte, aunque sepas que es por una buena causa, eso te deprime. Incluso llegué a llorar y a como que «Okay. Si me tengo que morir, me tengo que morir"”
Participant \#9 expressed the fear of an unknown disease course following diagnosis but also noted his relief from expected immunity after recovery.

"It was kind of scary and then the fear of the unknown. Sort of not wanting to believe that that's what happened and maybe slightly relieved that I didn't have to worry about it anymore [being immune to COVID]. But concerned about the future, immediate future."

Participant \#9: Older adult, White male. Exposure: Not reported Symptom onset: Spring 2020. Symptoms: Fever. Persistent symptoms: None. Health score: None reported. Mental Health: Not reported. Treatment: Tylenol and Ibuprofen.

Participant \#5 shared his struggle with depression, compounded by social isolation due to his diagnosis. His fear of dying alone led to a psychiatric emergency requiring hospitalization.

"When I was sick I had the news on a lot, mostly just CNN. I had been isolating before. I mean, I didn't do a great job at the sheltering in place. But when I had to self-isolate because I was ill, I had to shut myself from anybody. Any food I had [was] delivered and, so, I had no reasons to go outside. So, I started to get depressed. And this is going to sound silly because you'd have to be in my head to understand, but I was really feeling sad...everything was compounding, like just with the news...I kept thinking I'm going to die. No one's seen me, nobody cares that they can't see me. So, I called...911 - well, there was the non-emergency number, but they did come and then they took me to the emergency [room]. And it was funny because one of the EMTs, whatever, he asked me what's wrong. I said, 'well, I really feel sad.' He said: 'Okay. We're going to take you in for sadness?' I said: 'Well, it sounds funny because the way you're saying it, but yeah, really I am"”

Participant \#5: Older adult, Latinx male. Exposure: Community spread. Symptom onset: Spring 2020. Symptoms: Fever, chills, fatigue, cough, shortness of breath, sore throat. Persistent symptoms: None. Health score: None reported. Mental Health: Not reported. Treatment: None.

Participant \#6 (described above) felt anxious and frustrated over his recovery process:

"At that point I was, like, I probably have it. But as far as recovering, that's what I was more worried about; like, when is this going to be over? Like I don't feel I' $m$ getting better. If anything, I'm declining. So, it was more of like a feeling of anxiousness and, like, frustration." 
Levels of stress, anxiety, and frustration among participants could be directly related to the fear of dying or uncertainty pertaining to the health consequences of COVID-19. Participant \#14 (described above) shared that he could identify the symptoms and knew it was COVID-19 and mainly worried about the possible progression of his situation:

"I knew that I had it probably. I guess, I don't know, it's just like, 'Okay.' At that time, I would have been a lot scared now because we know how crazy it can be and then people fall off a cliff. We didn't know any of that back then, so I was like, 'You know, as long as I'm not dying then I guess I'm not dying'...I was worried because I had done enough research to understand that the receptors where your taste, where your smell, are very close to the brain and the central nervous system so it's like, 'Oh God, what if it gets into my brain. We don't know anything about this.,"

\section{HIV and COVID-19}

Eight participants were living with HIV and had recovered from COVID-19. Most were very attuned to early concerns of being at higher risk for severe COVID-19, although the fear of having more severe outcomes in this population attenuated over time with more data. Overall, participants noted that the fact that they were living with a co-infection of HIV facilitated them seeking information, staying vigilant, and following public health guidelines.

Participant \#23 stated feeling very fortunate, despite "my condition" [HIV], having had a few critical days when he felt deep anguish ("con mucha angustia"), and compared himself to other people of different ages he knew or had heard of that died of COVID-19, including two family members in Mexico.

Participant \#23: Older adult, Latinx gay male. Exposure: Community spread. Symptom onset: Summer 2020. Symptoms: Fever, chills, fatigue, cough, shortness of breath, sore throat, muscle aches, loss sense of smell, headaches, irritability. Persistent symptoms: Headache. Health score: 50 out of 100. Mental Health: Moderately anxious and depression during illness. Treatment: None reported.

Participant \#5 (described above) felt at higher risk because of his HIV status and additional comorbidities:

"I kept thinking I was one of the ones that if you got it, it's really not going to look good for you. I've had two heart attacks. I have HIV...viral load is not so great. Yeah, just didn't think it would bode well for me to have the COVID-19."

He explained that usually he struggled with adherence to his HIV treatment but that while recovering from COVID-19, he tried to regularly take his medications "with a purpose," having heard on the news that antiretrovirals may have a protective effect.

"I'm not really good at taking my pills, so that's a separate problem, but I took them as much as I would probably have ever taken them. I started to hear on the news something about the HIV medications or it's kind of - it was good to - you could combat the virus. I don't know. There's something in there, some component. So I thought: Oh, God, you better really take your meds",

In most cases, participants stated that their HIV care providers called them regularly to provide support and reassurance. Participant \#19 (described further above, Latinx gay male) explained that his doctor had reassured him that his HIV would not affect his recovery process.

"My primary doctor, she is an infectious disease specialist, only saw me on a video call and told me: 'If you don't feel well go to the E.R.' I didn't call her, she called me. And she gave me hope: 'I have patients who have survived having HIV. HIV has nothing to do with Covid. You are not going to die' and all that."“Mi doctor primario, sí, ella es especialista en infecciones, solamente me vio por video llamada y me dijo: 'Si te sientes mal ve a emergencia. Yo no la llamé, ella me llamó. Y ya me dio esperanza: 'Yo tengo pacientes que han sobrevivido teniendo VIH. Entonces, el VIH no tiene nada que ver con COVID. No te vas a morir," y todas esas cosas."

Participant \#19: Middle-aged adult, Latinx gay male. Exposure: Travel within the U.S. Symptom onset: Spring 2020. Symptoms: Fever, chills, fatigue, cough, shortness of breath, runny nose, sore throat, muscle aches, loss of smell, and headache. Health score: 20 out of 100. Mental Health: Not reported. Treatment: None reported.

Participant \# 10 explained that he initially had nose bleeds and headaches, but not having seen those in the list of COVID-19 symptoms, he did not call his HIV provider because he was afraid he would be told he had COVID-19. However, he acknowledged that he could have addressed this concern if he had contacted his HIV care provider.

"Now that I look back on it, I was just afraid to call the doctor. I didn't think it was going to be COVID. I thought that, because I didn't see nosebleeds on the list, and I don't remember seeing headaches, so I thought it was just going to be something other than that, and it would be related to my HIV, and then I'd be even more afraid."

Participant \#10: Older adult, Asian male. Exposure: Unknown. Symptom onset: Spring 2020. Symptoms: Fever, chills, fatigue, cough, shortness of breath, runny nose, 
muscle aches, nausea, vomiting, trouble concentrating, headaches. Persistent symptoms: Trouble concentrating. Severity: Not reported. Mental Health: Not reported. Treatment: Hospitalized and reported azithromycin, albuterol.

Participant \#10 expressed the feeling of being afraid of dying from COVID-19, but the support from his neighbors and friends, his family to some extent, and knowing that a person delivering food from Meals on Wheels (non-profit organization providing food assistance) was on the other side of his closed door, sustained him during his recovery process. He explained that his family was concerned for him but qualified his family support by saying they did not know how to deal with a crisis and had asked him whether he had made "arrangements" in preparation for his death. He noted that he only recently disclosed his HIV status to his family, which may have influenced their reaction.

"One of the things about when you're sick, after the diagnosis and you're in quarantine, you kind of start to give up. I started to think that, maybe it's just faster to just take care of it, to end it. Because, all I'm doing is sitting here and being sick. You're just thinking you're going to die. There's nothing saying that you're going to live, and I have HIV, I'm in a high risk category. Nothing was giving me any sense that I was going to live. So, why would I want to go through this, and just continue to keep going through this? That's why it was important for me that, when the Meals on Wheels people came, that little bit of contact with the real outside world and not through Zoom, it helped a lot. I'd wait until they'd come to deliver the food. All they'd say is, 'Your food is here,' and I'd say, 'Thank you,' but I'd look forward to it."

Like all participants in our study, participant \#10 was trying to reconcile uncertainty around immunity and risk of reinfection, which was yet to be determined in the scientific literature at that time. Like other participants, he was actively seeking health information through a local and well-known HIV-related institution in the area. Further, he deliberated over whom to tell he had had COVID-19 in anticipation of community stigma. He emphasized the importance of the lessons learned through time from the HIV epidemic and wanted to acquire the skills to manage his fear and stigma related to COVID-19 and how to reinsert him back to social life:

"What I need to understand is how people with HIV assimilated back into the community. In the early days, how did they do that? I don't know how to do that, and that's the thing I'm most afraid of, that I won't be able to... I'm afraid that I'm going to isolate myself further, because I don't know how to join back in, and how to deal with the stigma. That I'm going to get more of it. I'm a realistic person. When people are afraid, if people are afraid, I'm going to get more of it. I need to know how to better handle that. My plan was to go to the SF AIDS Foundation, to see if they have some ideas and thoughts on how to re-assimilate, when you're faced with the fear of others."

Importantly, a participant who was not living with HIV compared the experience with COVID-19 to the initial reactions during the HIV epidemic in the 1980s. Participant \#14 (described above) stated:

"I would just say it's very scary. It feels like, it must feel like when people were getting diagnosed with HIV early on. We didn't know what it was and it's very unclear what it means for you."

Participant \#11 described the lack of knowledge of the possible impact of a novel virus in society in general. Similarly, another participant talked about the uncertainty and fear associated to a new virus but added that the COVID-19 and HIV epidemics are natural phenomena.

"When HIV first came out there was a lot unknown about HIV, and there's still a lot of unknown about HIV. Just because it's unknown doesn't mean that it's to be feared. Maybe the unknown is livable. I mean, space is unknown, man on the moon is unknown, there's lots of unknown and life is unknown. It's a fact of life."

Participant \#11: Older adult, White male. Exposure: Unknown. Symptom onset: Spring 2020. Symptoms: Fatigue, sore throat, loss sense of smell, trouble concentrating. Persistent symptoms: Trouble concentrating. Severity: Not reported. Mental Health: Not reported Treatment: None.

In summary, participants who had been living with HIV had a heightened awareness of the risks for severe COVID19 disease, drew lessons for coping from the HIV epidemic, and also displayed high levels of health information-seeking behavior, in part due to access to HIV and other health information and wrap-around service support.

\section{Persistent Symptoms}

We concluded all interviews by asking each participant about their current health concerns as compared to the period of time during acute illness. Although the idea of "long COVID" or post-acute sequelae of COVID-19 was only beginning to emerge at the time of the interviews, we were able to collect unique insights related to experience with persistent symptoms. In some participants, persistent symptoms were intense and specific, but there remained uncertainty about the recovery process. For example, 
participant \#1 (featured above) who was intubated noted ongoing issues with his breathing and fatigue.

Participant \#1 - "Well, now I've got a complication with the scar tissue....I've got an inhaler here, like, that I keep with me. I keep checking my blood pressure periodically. I was checking my pulse oximeter all the time. Now I'm down to checking it every other day, every third day. But this thing is constantly bugging me because I got mucus that gets trapped that's hard to cough it out....I'm very tired. I get very fatigued and tired. I don't - I don't have my normal stamina, you know, going through the day....I'm at - I'm at 50 percent level."

Participant \#15 (featured above), a middle-aged White heterosexual female, noted similar issues with requiring to monitor her blood pressure.

"I still have quite a bit of issues. Actually, I have a Holter monitor on right now because my blood pressure is still... after this, it still drops quite a bit low. And my heart rate is still very high. And my energy levels are... I can do something one day. But the next two days, I'm just out of energy, super dizzy, super sick that I mostly just want to sleep. I'm not back to my normal self. And the smells, I can smell certain things, but not like before...And I still get that yucky taste. And that yucky taste... unfortunately, not back to my normal self. I want to, so bad."

In other cases, such as participants \#13 and \#19 (also featured above), they were managing persistent cardiopulmonary and neurocognitive symptoms, both of which featured high uncertainty.

Participant \#13 - “Oh, okay. The long term effects...I'll say that the only thing that I probably still feel here and there is just this chest tightness that I have sometimes that I feel in the nighttime before I'm going to bed, and it just feels like it's just stuck right here, this breath, and I'm just taking in some more deeper breaths. And then it goes away."

Participant \#19 - "What worries me now is that I get tired. Yesterday I couldn't run even four blocks ... Right now about 30 percent. The other thing that worries me is that COVID has affected my brain in a way that stresses me..." "Lo que me preocupa ahora es que me canso. Ayer no pude correr ni cuatro cuadras...Ahorita como un 30 por ciento. Lo otro que me preocupa es que el COVID haya afectado mi cerebro de una forma que me estrese...".

Other data showed a clear connection between physical symptoms and mental health, particularly around non-specific symptom features (e.g., persistent fatigue) and unclear prognoses. Participants \#4, \#14, \#15, and \#23 (all featured above) exemplified these insights in the following quotes:

Participant 4-"I am definitely functioning at a lower level. A week ago, I would have said $75 \%$. Today, maybe 80 to $85 \%$ but probably, most of the time, only about $80 \%$...I'm not sure if it'll ever go back to $100 \%$ because I don't think anything in my life...will ever be the same again."

Participant 14-"Yeah, long term impacts, relapse...like two weeks ago, had that neck and arm pain again....But feeling like, 'I still don't feel like myself and that's very worrisome.' I definitely have days where I feel like very fatigued and almost sick but I don't know how to describe that."

Participant 15-"For a long time, I was still having stomach cramps, and I was having diarrhea two or three times a day. I have insomnia. I don't know what else... I think I'm trying to be patient, but I think the unknowns kind of make it a little scarier just because why am I still having symptoms two months later on something that the other two people in my family have fully recovered from. This feels weird to me."

Participant \#23-“"And what also worries me and is uncomfortable are also the headaches, which do not go away. [medical provider] states 'Well, I don't know' ...but... it goes away and then comes back again. And I don't know what I can do."

"Y lo que sí me tiene también preocupado y es incómodo también son los dolores de cabeza, que no se van. [medical provider] states «Bueno, no sé»...pero... se va y después regresa otra vez. Y no sé qué puedo hacer."

Almost all of our participants were still experiencing the physical or emotional aftermath of their COVID-19 infection. For example, participant \#20 eloquently summarized the experience of others and noted that the improvements in mental health are needed to feel fully recovered from COVID-19.

"Maybe 80, 90\% because...the body is no longer $100 \%$...but maybe $10 \%$ is mental. So that also counts because if you are not mentally well as well, then you can be affected."“Quizás un 80, 90\% porque siempre - ya el cuerpo ya no es el $100 \%$....Tengo, pero como quizás el $10 \%$ sea mental. Entonces, eso también cuenta porque si no estás bien también mental, entonces puedes ser afectado."

Participant \#20: Middle-aged Latino male. Exposure: Unknown. Symptom onset: Spring 2020. Symptoms: Fever, fatigue, cough, muscle aches, diarrhea, headaches Persistent symptoms: Fatigue. Severity: Not reported. Mental Health: Not reported Treatment: Hospitalized.

\section{Discussion}

Our qualitative data from English- and Spanish-speaking individuals across a variety of disease presentations shows the challenges of understanding and evaluating the variability 
in the illness and recovery experience with COVID-19. Overall, three findings emerged that were central to the acute experience with COVID-19 and are useful for continued research on post-acute sequelae of COVID-19. First, all individuals had to manage pervasive uncertainty in multiple domains, including processing the possible consequences of asymptomatic infection; uncertainty regarding the course following symptomatic infection in terms of cognitive function and memory loss; and the ongoing recovery process with persistent symptoms, especially among those requiring hospitalization. Second, given that COVID-19 is a novel disease, we found high levels of health information-seeking behavior (e.g., calling medical providers, sources of trusted information). Importantly, information-seeking behavior served as a proactive coping strategy for managing the unpredictability of the illness at the time and facilitated by access to medical care. The resulting information-sharing participants received from medical staff and providers led to receipt of instrumental, moral, and social support. Lastly, despite different symptom profiles and severities, all participants shared similar levels of psychological distress. This was especially clear among those with persistent symptoms, likely related to the underlying uncertainty they were attempting to cope with both with regard to COVID-19 recovery and the broader socio-economic impact of surviving a global pandemic.

\section{Implications}

Recently established cohort studies show that symptoms among people with post-acute sequelae from COVID-19 are frequently non-specific: fatigue, myalgias-arthralgias, and neurocognitive (i.e., headaches, "brain fog") [23, 24] suggesting that managing patient uncertainty will be a part of the overall coping process. Our data shed light on the intensity of the illness experience, even across initial symptom strata, and suggest that psychological adjustment will be key in recovery. While neurocognitive post-acute sequelae is an emerging and less understood area [25], there are implications for these sequelae exacerbating psychological distress resembling post-traumatic stress (i.e., arousal, worry, intrusive thoughts) given that many participants had near-death experiences [26-28]. But importantly, in identifying frameworks to help understand the experience of a new disease with a high degree of uncertainty, we found lessons can be drawn from management of chronic diseases (e.g., pulmonary disease, liver disease, and HIV).

How participants processed and coped with their illness, and managed persistent symptoms and uncertainty, showed similarities to the dimensions of the healthcare empowerment model, originating out of work in HIV, cancer, and cardiovascular disease. This model outlines that coping with a novel disease will require tolerating and navigating a level of uncertainty through supportive actions to stay informed and engaged with a treatment plan and team [11, 29]. Other research from pulmonology and gastroenterology [30, 31], including interventions and qualitative research, points to use of cognitive and behavioral strategies to manage psychological distress over the unpredictability of illness and prognoses and recommends communication with healthcare providers about their own clinical uncertainties. As participants' experiences highlighted, there will be a need to provide information and continuous support to persons with post-acute sequelae to ensure they feel secure along the path to recovery.

\section{Limitations}

Our study has several limitations. First, we recognize that the majority, but not all, of our sample were male and White/ Caucasian, which does not represent the populations hit hardest by the COVID-19 pandemic, particularly African Americans and Latinx individuals and other communities where COVID-19 merely compounded other social and structural inequities [32]. While we do have some representation of Latinx individuals that offers insight into what their experience with COVID-19 was, we were not able to deepen on issues related to the social inequities that increase health disparities that escalated the risk and severity of COVID19 among frequently marginalized populations [32]. Second, our study was completed amid the first two waves of COVID-19 cases in the USA, and new information and details about the virus, symptoms, treatments, and sequelae were evolving daily. Third, our participants were engaged in the start of a newly developed cohort study; these engaged participants may differ from other populations of individuals who have recovered from COVID-19. Because the study took place in an infectious disease (including HIV) care and research center, which took aggressive measures to shelterin-place earlier than other major cities, and many participants were already linked to the medical setting formally, there are likely differences in experiences compared to persons with limited access to medical care. However, our findings continue to be applicable given the convergent themes that emerged across all narratives and that these themes continue to apply to individuals suffering from "long COVID." Lastly, we have no reason to believe that the results depend on other characteristics of the participants or context.

\section{Conclusion}

We were able to leverage personal narratives of experiences with asymptomatic infection, symptomatic infection, including hospitalization, and HIV co-infection, to identify patterns in how the disease was experienced and gain insights 
into the recovery process. Psychological distress was elevated regardless of symptomatology. Information-seeking behavior, health empowerment, and social support were enabling factors toward recovery for our participants. These data help shed light on the management of emerging post-acute sequelae of COVID-19, including addressing issues with disease uncertainty, mental health, and persistent symptoms.

Acknowledgements We are grateful to the LIINC study participants and to the clinical staff who provided care to these individuals during their acute illness period. We acknowledge LIINC clinical study team members: Tamara Abualhsan, Mireya Arreguin, Jennifer Bautista, Monika Deswal, Ruth Diaz Sanchez, Heather Hartig, Marian Kerbleski, Sadie Munter, Lynn Ngo, Fatima Ticas, and Meghann Williams. We acknowledge LIINC leadership team members Bryan Greenhouse, Isabel Rodriguez-Barraquer, and Rachel Rutishauser.

Author Contribution EIS, AM, MJP, and JAS designed the qualitative study. MJP, JDK, TJH, SGD, and JNM designed the parent cohort, which is supported with funding from MAS, MG, TJH, and SGD. MJP, RH, VT, EAF, YH, and LT identified participants for referral and collected clinical data. EIS and AM performed interviews, collected data, and with JS performed the qualitative analysis. EIS, AM, MJP, and JAS wrote the initial draft of the manuscript, which all authors reviewed and edited. All authors approved the final manuscript.

Funding This work was supported by the NIH/NIAID 3R01AI14100303S1 [to TJH], NIH/NIAID R01AI158013 [to MG and MS], and by the San Francisco General Hospital Department of Medicine and Division of HIV, Infectious Diseases, and Global Medicine. MJP is supported on NIH T32 AI60530-12 and by the UCSF Resource Allocation Program. JDK is supported on NIH/NIAID AI135037. EIS was supported by NIH-NIMH T32 MH019105. AM and part of this work was assisted by the UCSF-Gladstone Center for AIDS Research NIH P30AI027763. JS was supported by K01MH113475 from the NIMH.

\section{Declarations}

Conflict of Interest The authors declare no competing interests.

\section{References}

1. Nalbandian A, Sehgal K, Gupta A, et al. Post-acute COVID-19 syndrome. Nature Med. 2021;27:601-15.

2. Allday E. Another scary thing about COVID: Survivors aren't fully recovering. San Francisco Chronicle. September, 28, 2020. https://www.sfchronicle.com/health/article/Another-scary-thingabout-COVID-Survivors-15601758.php.

3. Brody JE. When symptoms of COVID-19 don't go away. New York Times. October 12, 2020. https://www.nytimes.com/2020/ 10/12/well/live/coronavirus-symptoms-covid-19-persistent.html.

4. Carfi A, Bernabei R, Landi F, et al. Persistent symptoms in patients after acute COVID-19. JAMA. 2020;324:603-5.

5. Gandhi RT, Lynch JB, del Rio C. Mild or moderate COVID-19. N Eng J Med. 2020;383:1757-66.

6. Stewart G. My experience with COVID-19 - not just another experience. The BMJ Opinion. Accessed on Feb. 1, 2021. https:// blogs.bmj.com/bmj/2020/07/20/grant-stewart-my-experience-ofcovid-19-not-just-another-experience/.

7. Yong, E. Long-haulers are redefining COVID-19. The Atlantic. August 19, 2020. https://www.theatlantic.com/health/archive/ 2020/08/long-haulers-covid-19-recognition-support-groupssymptoms/615382/.

8. Pope C, Mays N. Qualitative research: qualitative research: reaching the parts other methods cannot reach: an introduction to qualitative methods in health and health services research. BMJ. 1995;311:42.

9. Holmes EA, O'Connor RC, Perry H, et al. Multidisciplinary research priorities for the COVID-19 pandemic: a call for action for mental health science. Lancet Psychiatry. 2020;7:547-60.

10. Greenhalgh T, Knight M, A'Court C, Buxton M, Husain L. Management of post-acute covid-19 in primary care. BMJ. $2020 ; 370, \mathrm{~m} 3026$.

11. Lambert SD, Loiselle CG. Health information-seeking behavior. Qual Health Res. 2007;17:1006-19.

12. Johnson MO. The shifting landscape of health care: toward a model of health care empowerment. Am J Pub Health. 2011;20:265-70.

13. Halvorsen K, Dihle A, Hansen C, Nordhaug M, Jerpseth H, Tveiten S, Joranger P, Knutsen IR. Empowerment in healthcare: a thematic synthesis and critical discussion of concept analyses of empowerment. Patient Educ Couns. 2020;103:1263-71.

14. Liu PL. COVID-19 information seeking on digital media and preventive behaviors: the mediation role of worry. Cyberpsychol Behav Soc Netw. 2020;23:677-82.

15. Teti M, Schatz E, Liebenberg L. Methods in the time of COVID19: the vital role of qualitative inquiries. Int J Qual Methods. 2020;19:1-5.

16. Eisinger RW, Lerner AM, Fauci AS. Human immunodeficiency virus/AIDS in the era of coronavirus disease 2019: a juxtaposition of 2 pandemics. J Infect Dis. 2021;XX:1-7.

17. Peluso MJ, Kelly JD, Lu S, et al. Rapid implementation of a cohort for the study of post-acute sequelae of SARS-CoV-2 infections/COVID-19. medRxiv. March 13, 2021. https://doi. org/10.1101/2021.03.11.21252311.

18. Guest G, MacQueen KM, Namey EE. Applied thematic analysis. Thousand Oaks, CA: SAGE Publications, Inc.; 2014.

19. Nowell LS, Norris JM, White DE, Moules NJ. Thematic analysis: striving to meet the trustworthiness criteria. Int J Qual Methods. 2017. https://doi.org/10.1177/1609406917733847.

20. Braun V, Clarke V. Using thematic analysis in psychology. Qual Res Psychol. 2006;3:77-101. https://doi.org/10.1191/ 1478088706qp063oa.

21. King N. Using templates in the thematic analysis of text. In: Cassell C, Symon G, editors. Essential guide to qualitative methods in organizational research. London, UK: Sage; 2004. p. 257-70.

22. Dedoose Version 7.0.23, web application for managing, analyzing, and presenting qualitative and mixed method research data (2016). Los Angeles, CA: SocioCultural Research Consultants, LLC. www.dedoose.com.

23. Logue JK, Franko NM, McCulloch DJ, McDonald D, Magedson A, Wolf CR, Chu HY. Sequelae in adults at 6 months after COVID-19 infection. JAMA Network Open. 2020;4: e210830.

24. Moreno-Pérez O, Merino E, Leon-Ramirez JM, et al. Post-acute COVID-19 syndrome. Incidence and risk factors: a Mediterranean cohort study. J Infec. 2021; 82: 378-383.

25. Hellmuth J, Barnett TA, Asken BM, et al. Persistent COVID19-associated neurocognitive symptoms in non-hospitalized patients. J Neurovirol. 2021;27:191-5.

26. Horesh D, Brown AD. Traumatic stress in the age of COVID-19: a call to close critical gaps and adapt to new realities. Psychol Trauma. 2020;12:331-5.

27. Kaseda ET, Levine AJ. Post-traumatic stress disorder: a differential diagnostic consideration for COVID-19 survivors. Clin Neuropsychol. 2020;34:1498-514. 
28. Mazza MG, De Lorenzo R, Conte C, et al. Anxiety and depression in COVID-19 survivors: role of inflammatory and clinical predictors. Brain, Behav Immun. 2020;89:594-600.

29. Wilson TE, Kay ES, Turant B, et al. Healthcare empowerment and HIV viral control: mediating roles of adherence and retention in HIV care. Am J Prevent Med. 2018;54:756-64.

30. Kimbell B, Boyd K, Kendall M, Iredale J, Murray SA. Managing uncertainty in advanced liver disease: a qualitative, multiperspective, serial interview study. BMJ Open. 2015;5:3009241.

31. Jiang X, He G. Effects of an uncertainty management intervention on uncertainty, anxiety, depression and quality of life of chronic obstructive pulmonary disease outpatients. Res Nurs Health. 2012:35:409-18.

32. Nydegger LA, Hill MJ. Examining COVID-19 and HIV: the impact of intersectional stigma on short- and long-term health outcomes among African Americans. Int Soc Work. 2020;63(5):6559. https://doi.org/10.1177/0020872820940017.

Publisher's Note Springer Nature remains neutral with regard to jurisdictional claims in published maps and institutional affiliations. 